\title{
Climate forecasts in disaster management: Red Cross flood operations in West Africa, 2008
}

\author{
Lisette Martine Braman, Maarten Krispijn van Aalst, Simon J. Mason, \\ Pablo Suarez, Youcef Ait-Chellouche and Arame Tall ${ }^{1}$
}

In 2008, the International Federation of Red Cross and Red Crescent Societies (IFRC) used a seasonal forecast for West Africa for the first time to implement an Early Warning, Early Action strategy for enhanced flood preparedness and response. Interviews with disaster managers suggest that this approach improved their capacity and response. Relief supplies reached flood victims within days, as opposed to weeks in previous years, thereby preventing further loss of life, illness, and setbacks to livelihoods, as well as augmenting the efficiency of resource use. This case demonstrates the potential benefits to be realised from the use of medium-to-long-range forecasts in disaster management, especially in the context of potential increases in extreme weather and climate-related events due to climate variability and change. However, harnessing the full potential of these forecasts will require continued effort and collaboration among disaster managers, climate service providers, and major humanitarian donors.

Keywords: climate, disaster, early warning, flood, preparedness, seasonal forecast

\section{Introduction}

Global climate change is increasing the risk of extreme weather and climate events such as droughts, floods, heat waves, and stronger storms (see, for example, O'Brien et al., 2006; van Aalst, 2006; Christensen et al., 2007). Societies will have to adapt to cope with changes in the climate system already set in motion by emissions of greenhouse gases currently in the atmosphere. Disaster management and humanitarian relief agencies will likely be called on to respond to increasingly frequent and severe weather- and climate-related disasters. To keep pace with a rising number of disasters, to save lives, and to use resources more efficiently, disaster managers will need to invest more in preparedness, early warning, and vulnerability reduction, rather than focusing primarily on response (van Aalst, 2006).

Global climate change projections for 2100 are striking: the Intergovernmental Panel on Climate Change (IPCC) predicts an average global temperature increase in the range of I.O-6.4 degrees centigrade $\left({ }^{\circ} \mathrm{C}\right.$ ) (IPCC, 2007), based on six emissions scenarios. Sea levels could rise by as much as one metre, and an intensification of the hydrological cycle in a warmer atmosphere is likely to make droughts and floods more frequent and intense (Christensen et al., 2007; Kleiner, 2010). Although climate change is already affecting risks and increasing uncertainties, for most purposes humanitarian planning is on a time scale of days, months, and years, or at most decades. 
Table 1 Forecasts at different time scales: useful information, forecast limitations, and guidance on appropriate actions

\begin{tabular}{|l|l|}
\hline Long term (century and decades) & $\begin{array}{l}\text { Global climate change projections (to 2100) and decadal predictions (for the } \\
\text { next 10-30 years). }\end{array}$ \\
\hline What the forecast tells you & $\begin{array}{l}\text { General trends (such as drier, hotter, wetter, changes in extreme events, sea } \\
\text { level rise, likely implications for health and livelihoods). Decadal predictions } \\
\text { provide more information on what is likely in a given region during the coming } \\
\text { decade due to climate variability and change. }\end{array}$ \\
\hline
\end{tabular}

Limitations of the forecast

Large uncertainty. Lack of specificity in terms of where and when impacts will occur.

Potential actions using available information

Identification of likely risks and vulnerabilities in your area. Coordination with partners and development of a long-term vision to expand capacity, reduce vulnerability, and minimise risks.

\section{Medium term (seasonal)}

Forecast type

Seasonal forecasts for temperature, precipitation, and cyclone activity. Seasonal forecasts typically cover three to four month periods and do not normally extend beyond 12 months into the future. They should be checked for monthly updates.

What the forecast tells you The chances that the coming season as a whole, and over a large geographic area, might exhibit average temperatures/accumulated rainfall/numbers of storms that are normal, above normal, or below normal. Some seasonal forecasts for extreme climate conditions also are available.

Limitations of the forecast

Seasonal forecasts are made at coarse resolutions, and thus do not reveal when and where, or even if, extreme weather events are likely to happen. Forecasts are not directly about individual extreme weather events, they are only about the general character of the coming few months. Forecast uncertainty remains great.

Potential actions using available information

\section{Short term (weeks, days, and hours)}

Forecast type

What the forecast tells you

Limitations of the forecast

Potential actions using available information
Combine the seasonal forecast with what you already know about your climate-for instance, if the forecast is for increased chances of above normal rainfall during the rainy season, it can be inferred that flood risk is heightened; if the forecast is for above normal temperatures during the summer, it can be inferred that heat wave risk is heightened. Ask what needs to happen to be prepared for these risks: do staff, volunteers, and communities know what to do? Are plans in place? Are communication systems ready? Are supplies sufficient and accessible? Can early warning systems be set up beforehand? Are partner agencies informed and ready? At the same time, monitor on shorter time scales in order to anticipate where and when elevated risks might become extreme events. 
In the context of these changing risks, disaster managers - the people working to prepare for and respond to a range of disasters in national governments, international organisations, and non-governmental organisations (NGOs) - may find it increasingly useful to monitor forecasts across time scales in order to prepare for shorter-term impacts associated with longer-term changes and natural fluctuations in climate.

The use of forecasts for decision-making in disaster management is not a new concept. Weather forecasts for temperature, precipitation, and wind are issued all over the world on short-term time scales of days to hours, informing disaster managers when to anticipate extreme weather events such as floods and tropical cyclones. Disaster managers also are informed regularly by climatic conditions. ${ }^{2}$ For instance, disaster managers in cold climates prepare for different risks than disaster managers in warm climates. In addition, it is common for disaster managers to anticipate different kinds of risks according to typical patterns in a particular season (such as wet or dry, hot or cold). However, natural climate variability (variations in the climate system that can last from months to decades) and unfamiliar changes due to global climate change require forecasts on a range of time scales to anticipate associated risks. Monitoring across multiple time scales allows disaster managers to obtain an overall picture of the risks for advanced preparation, and then to use forecasts on shorter time scales to anticipate more precisely where and when an extreme event might occur and how severe it might be. Table I illustrates different time scales of forecast information, indicating what information the forecasts at various time scales can and cannot provide. Table I describes as well the different types of actions that could be triggered by forecasts at the various time scales.

\section{Historical challenges of using climate forecasts in disaster management}

Scientists have been issuing medium-term or seasonal forecasts (predicting the average weather conditions for the next few months) for the past two or three decades (Patt, Ogallo and Hellmuth, 2007a; Mason, 2008). This development stems largely from an ability to predict the El Niño-Southern Oscillation (ENSO) and some of its global consequences, including droughts and floods. In early I997, when evidence of the possible development of a strong El Niño event began to emerge, the scientific community made its first serious attempt to communicate forecasts of its expected impacts to sector-specific users. Regional Climate Outlook Forums were organised to produce probabilistic, consensus-based, seasonal precipitation forecasts of how El Niño might affect rainfall in various regions. Forecasts were made up to six months in advance and received significant media attention (IFRC, I999; Hossain et al., 2000; Adeel and Glantz, 200I; Glantz, 200I). These 'Climate Outlooks' represented a significant step forward in the dissemination of seasonal forecasts for sector-specific decision-making (Buizer, Foster and Lund, 2000). However, there were few cases during the 1997-98 El Niño event in which this forecast information translated into action (IFRC, I999; Hossain et al., 2000; van Aalst et al., 2000; Adeel and Glantz, 200I; Glantz, 200I). 
Advances in the dissemination of seasonal climate forecasts since the I997-98 El Niño have continued. However, there remain only a few documented examples of successful use of seasonal forecasts for improved disaster management and planning (Hellmuth et al., 2007; Patt, Ogallo and Hellmuth, 2007a; Patt and Winkler, 2007b). Generally, these early warnings are not translating effectively into early action (Broad and Agrawala 2000, Patt and Winkler, 2007b; IFRC, 2009).

There are many reasons for this poorly developed use of seasonal forecasts for disaster management. First, there are a number of issues concerning the nature of the forecasts themselves. Notably, climate models only capture general trends in temperature and precipitation, and they lack the spatial and temporal specificity of short-term weather forecasts indicating where and when within the forecast area and time period extreme rainfall events might occur. Predictability also varies from place to place, season to season, and year to year (Mason, 2008). In addition, forecast uncertainty is high, making it difficult for disaster managers to commit resources to prepare for a particular outcome when there is still a good chance that benign conditions or unanticipated events will occur. High forecast uncertainty also contributes to difficulty in communicating climate forecasts in a way that triggers appropriate and timely action.

Second, there are a number of institutional and cultural barriers to taking action based on climate forecasts. The predominant financial mechanism in place to fund relief operations is voluntary contributions from the donor community. Such donations are rarely prompted by pre-emptive early warning systems, but rather by news of the impacts once a disaster is well under way (Broad and Agrawala, 2000; Haile, 2005; The Economist, 2005). To complicate matters, political will and the traditional focus on response within the culture of disaster management also present challenges (van Aalst et al., 2000; Haile, 2005; Tadesse et al., 2008).

Finally, issues related to capacity and communication also can limit effective translation of warnings into action. An important prerequisite for the successful use of seasonal climate information is the establishment of strong links between early warnings and actions at the community level. This can take years, but ongoing efforts in Mozambique, for example, are yielding notable reductions in death tolls as a result of severe flooding - the government there began using seasonal forecasts in I999 (Hellmuth et al. 2007; DFID, 2009; IFRC, 2009).

\section{Early warning, early action}

Early warning, early action (EWEA) is one strategy developed to help disaster managers benefit from the various types of information that forecasts at different time scales have to offer. EWEA is defined as '[r] outinely taking humanitarian action before a disaster or health emergency happens, making full use of scientific information on all timescales' (IFRC, 2008a, p. I). Through EWEA, disaster managers utilise long- and medium-range forecasts to consider potential implications for their region and to develop a set of 'no-regrets' strategies that lay the groundwork for the implementation of increasing levels of preparedness according to a progression of forecasts on shorter time scales (such as Io-day, weekly, daily). No-regrets actions 
(including the drafting of flood contingency plans, the training of volunteers, or pre-positioning of non-perishable relief items) are low-cost efforts that do not go to waste if the forecasted event does not take place-in the sense that they will remain useful in future disasters likely to happen sometime in the coming few years. This approach can be particularly helpful in developing countries where there are not enough resources to maintain a high level of preparedness for all types of disasters at all times. If disaster managers know droughts or floods are likely in a coming season, they can allocate better limited resources for more strategic preparedness and improved response.

The EWEA concept aligns with increasing emphasis within the disaster risk management community on preparedness, awareness, and risk reduction (see, for example, the Hyogo Framework for Action, 2005-2015: Building the Resilience of Nations and Communities to Disasters). ${ }^{3}$ The scientific community also has recognised the need to connect better forecast information and products to user needs for decisionmaking and enhanced preparedness. At the 2009 World Climate Conference-3, information providers resolved to undertake a Global Framework for Climate Services to strengthen the provision and employment of climate predictions, products, and information worldwide (WMO, 20IO). Recent advances in observational capacity, scientific understanding, and computer modelling of dynamic climate processes have resulted in forecasts with reasonable skill at various time scales, supporting linkages between the disaster management community and providers of climate and weather information (Suarez, 2009).

This paper provides an example of how a seasonal precipitation forecast was used by the Red Cross for improved flood preparedness and response in 2008. The case study comes from the International Federation of Red Cross and Red Crescent Societies (IFRC)'s West and Central Africa Zone (WCAZ). The IFRC supports all I86 National Red Cross and Red Crescent Societies, which are auxiliary to their national governments, in managing natural and man-made disasters in non-conflict situations. The IFRC's global headquarters are in Geneva, Switzerland, complemented by zonal, regional, and country offices that provide direct support to the National Societies. The IFRC's WCAZ is based in Dakar, Senegal, and supports 24 National Societies in the region via capacity-building and coordination in times of crisis (such as disasters or epidemics), including the coordination of regional response teams as well as of appeals to the donor community (issued through the Geneva-based headquarters). The role of the IFRC at the zonal level is generally larger in regions with lower capacity than in regions where governments themselves and their National Societies are able to respond to disasters on their own.

\section{The WCAZ and Early Warning, Early Action in 2008}

In 2008, the IFRC in West Africa implemented actions based on seasonal rainfall forecasts that saved lives and resources. In addition to having a meaningful impact on communities at risk, the experience in West Africa has provided a potential framework 
for translating climate forecasts into early action though the use of multiple forecasts on multiple time scales, in conjunction with 'no regrets' early actions. The information on events and results presented are largely based on an evaluation of the IFRC WCAZ's 2008 flood preparedness and response activities, commissioned by the IFRC WCAZ in early 2009 (Braman, 2009).

\section{Regional context}

In recent years, severe floods have killed thousands of people and caused significant material damage in Central and West Africa (IFRC, 2008b). Urban settlements developed on flood plains during the droughts of the I970s and I980s are now especially vulnerable and frequently affected by floods (Tall et al., 20I2).

Despite considerable uncertainty regarding the likelihood of changes in annual rainfall in the region, the IPCC suggests that floods are likely to increase in frequency with climate change: 'A general increase in the intensity of high-rainfall events, associated in part with the increase in atmospheric water vapour, is expected in Africa' (Christensen et al., 2007, p. 87I).

West Africa suffered the worst flooding in decades in 2007. More than 300 lives were lost and more than 800,000 people were affected as the floods destroyed crops,

Figure 1 Annual number of floods in West Africa, 1970-2008

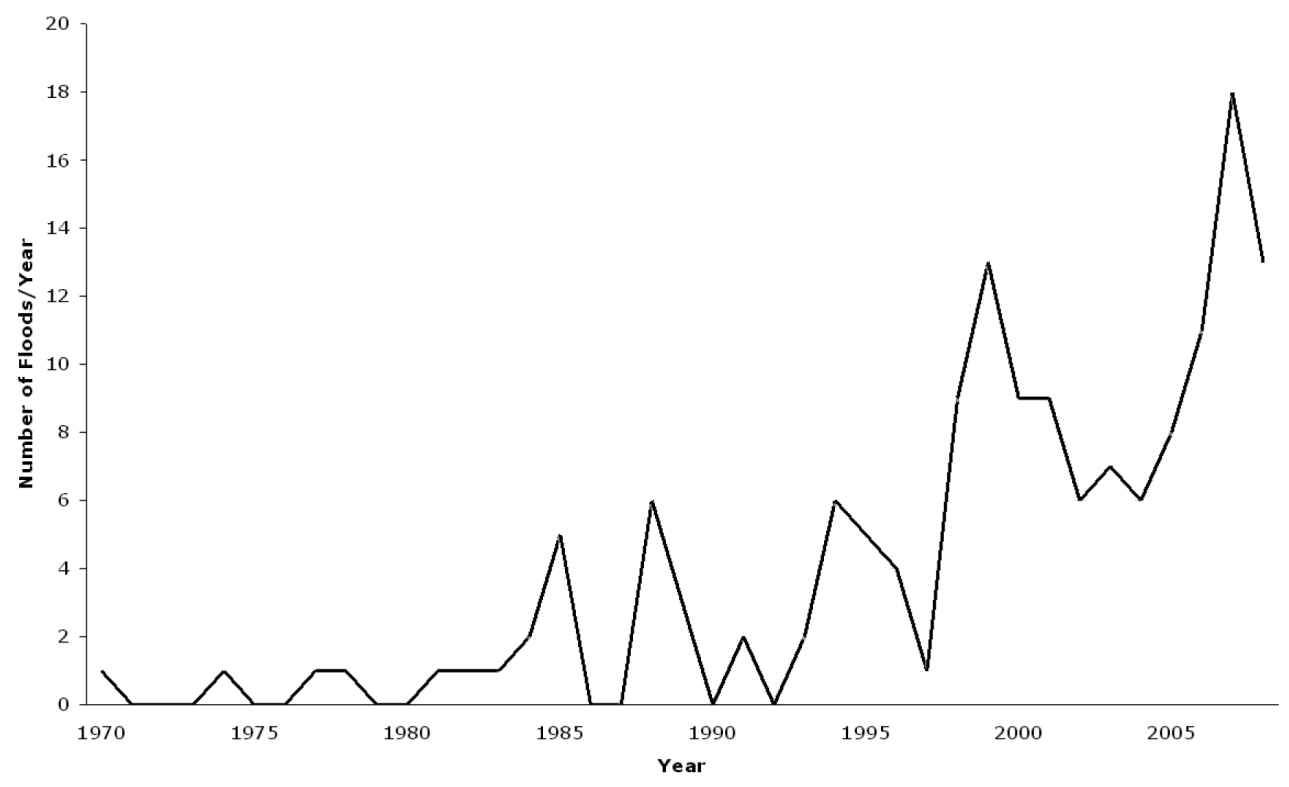

Note: data covers the following West African countries: Benin, Burkina Faso, Cape Verde Islands, Cote d'Ivoire, Gambia, Ghana, Guinea, Guinea Bissau, Liberia, Mali, Mauritania, Niger, Nigeria, Senegal, Sierra Leone, St Helena, and Togo. 'For a disaster to be entered into the database at least one of the following criteria must be fulfilled: Ten (го) or more people reported killed; Hundred (IOо) people reported affected; Declaration of a state of emergency; Call for International Assistance'.

Source: Emergency Events Database (EM-DAT), Office of US Foreign Disaster Assistance/ Centre for Research on the Epidemiology of Disasters, Université Catholique de Louvain, Brussels, Belgium (www.emda.net). 
Figure 2a IRI seasonal precipitation forecast

IRI Multi-Model Probability Forecast for Precipitation for June-July-August 2008, Issued May 2008

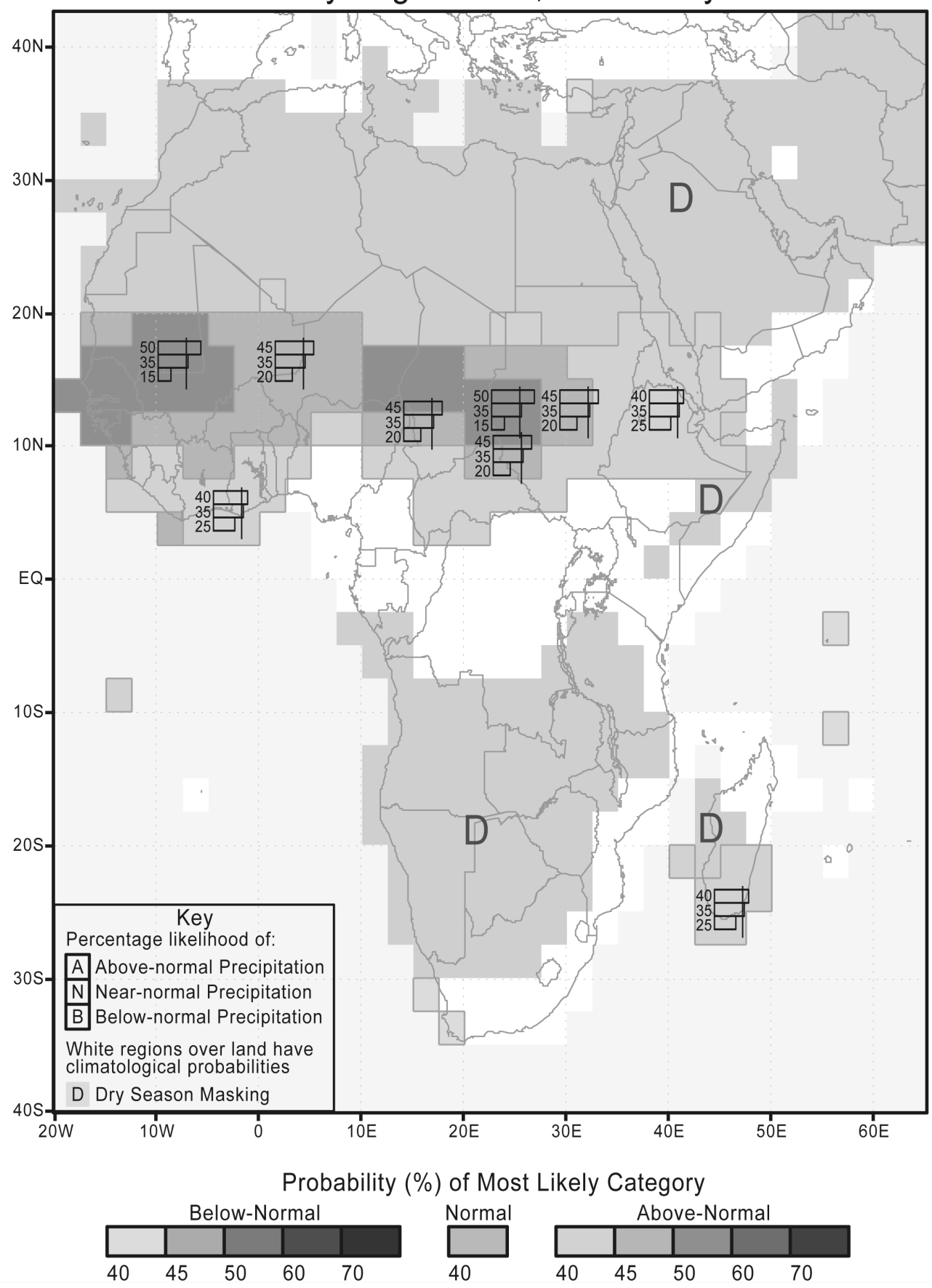

Source: IRI Net Assessments Forecasts, http://portal.iri.columbia.edu/portal/server.pt?open $=5$ I $2 \&$ objID $=944 \&$ PageID $=7613 \&$ cached $=$ true $\&$ mode $=2 \&$ userID $=2$ (accessed on 5 September 201 2 . 
Figure $\mathbf{2 b}$ IRI extreme precipitation forecast

\section{IRI Multi-Model Probability Forecast of Extreme Precipitation} for June-July-August 2008, Issued May 2008

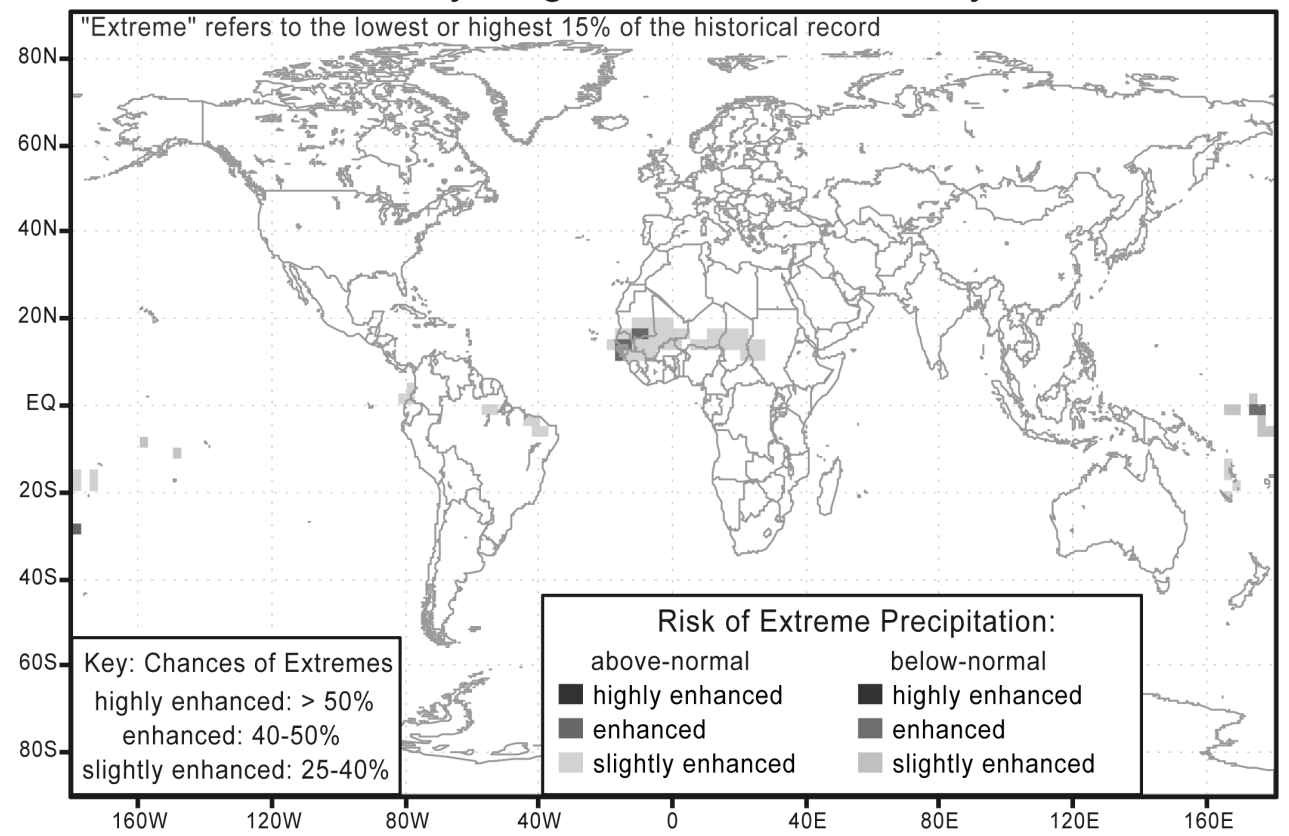

Source: IRI Net Assessments Forecasts, http://portal.iri.columbia.edu/portal/server.pt?open $=5$ I 2 \&objID $=944 \&$ PageID $=76 \mathrm{I} 3 \&$ cached $=$ true $\&$ mode $=2 \&$ userID $=2$ (accessed on 5 September 20I 2$)$.

Figure 2c PRESAO-11 precipitation forecast for July, August and September (updated on 27 June 2008)

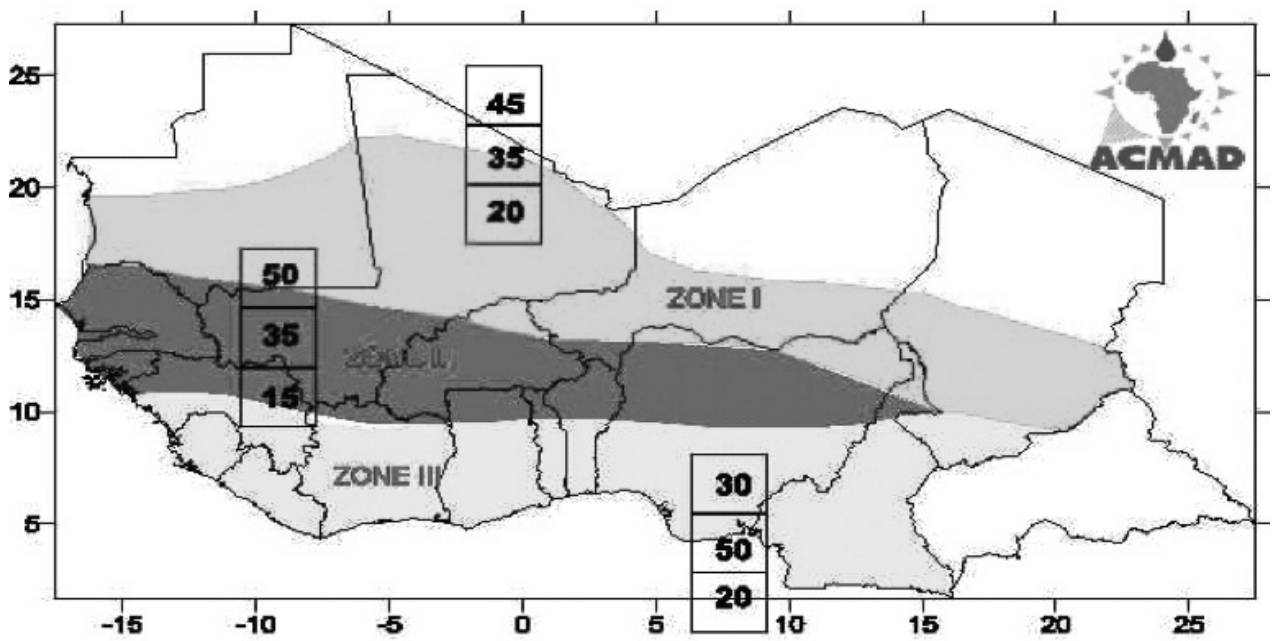

Note: the numbers in vertical boxes indicate the probability that rainfall will be above-normal (top box), normal (middle box), and below-normal (bottom box) for each zone.

Source: ACMAD, 2008. 
Table 2 Timeline of Early Actions in 2008

\section{May}

The FRC's WCAZ held a Flood Preparedness Meeting for Central and West Africa. A major outcome was an action plan to develop contingency plans, country-specific risk maps, an early warning system, partnerships, and better coordination for preparedness and mitigation of impacts.

The Disaster Management Coordinator of the FRC WCAZ attended the PRESAO.

\section{June}

The FRC WCAZ held a five-day Regional Disaster Response Team (RDRT) Team Leader's Training. It was designed to provide leaders with skills and tools to ensure coordination of relief operations and to support Red Cross and Red Crescent National Societies during disasters. In addition, logistical preparations, including the securing of visas and medical insurance, were made in advance so the RDRT Team Leaders could be deployed quickly where needed.

\section{July}

The FRC WCAZ issued its first-ever emergency appeal in advance of a probable disaster, to fund preparedness activities throughout the region. However, the donor community did not have the systems in place to fund forecast-based preparedness actions. Standard mechanisms for fund transfers are aimed either at post-disaster operations or general development or risk reduction measures that are independent of predictions. The FRC WCAZ therefore used funds more immediately available from the Federation's internal fund, the Disaster Relief Emergency Fund (DREF).

Knowing that relief supplies commonly take between two and three weeks to arrive from the logistics unit in Dubai, United Arab Emirates, the FRC WCAZ pre-positioned relief items (such as blankets, cholera kits, kitchen sets, soap, tents, water and sanitation kits) in more accessible locations (Accra, Ghana; Dakar, Senegal; Yaoundé, Cameroon) that would enable beneficiary needs to be met within $24-48$ hours.

Seven of the nine flood-prone countries prepared flood contingency plans.

August and September

The first shipment of emergency stocks (blankets) reached the warehouses. Shipments continued until late September (when cholera and kitchen kits arrived). However the stocks were insufficient for the season, and in response to the floods in Benin and Togo, the FRC WCAZ launched a revised appeal.

Source: Braman, 2009; Tall et al., 2012.

homes, and infrastructure. Humanitarian agencies scrambled to provide relief. However, the floods largely caught them off guard. Taking stock of lessons learned from the devastation and damage in 2007, disaster managers at the IFRC WCAZ contacted the Red Cross/Red Crescent Climate Centre (RCCC), a reference centre on climate risk management for the International Red Cross and Red Crescent Movement and its partners. Disaster managers and the RCCC also began to discuss changing disaster risks due to long-term global climate change. Given that there is considerable uncertainty about changes in rainfall related to climate change in this region, the RCCC recommended investing more in preparedness, including better use of information at medium- and short-term time scales.

To enhance the use of climate and weather information across time scales within the IFRC, the RCCC helped to facilitate a partnership between the IFRC WCAZ and the African Centre for Meteorological Applications for Development (ACMAD). A partnership had also been formed between the IFRC and the International Research Institute for Climate and Society (IRI) at Columbia University, New York, in late 2007. The goal of these partnerships is to help disaster managers and climate scientists 
work together to improve the application of climate information to humanitarian work and de facto to enhance the disaster risk management programme in the IFRC WCAZ.

\section{West Africa disaster management operations in 2008}

The establishment of these partnerships was timely, since the May 2008 seasonal forecasts indicated once again an augmented probability of above-normal rainfall during the upcoming June-September rainy season, implying above-normal flood risk. Figures $2 \mathrm{a}, \mathrm{b}$, and $\mathrm{c}$ show precipitation forecasts issued in spring 2008 by IRI, as well as by ACMAD, whose consensus-based forecast was the product of the Regional Climate Outlook Forum for West Africa, Cameroon and Chad (PRESAO).

This time, the IFRC WCAZ responded to the early warning with a number of early actions, including pre-positioning relief items, improving disaster response capacity through training, development of flood contingency plans, and launching the first-ever pre-emergency funding requests for preparedness activities and response based on a seasonal forecast. Table 2 shows the timeline of these early actions.

The first floods occurred in late June in Gambia and Senegal, just days into the Regional Disaster Response Team (RDRT) Team Leader's Training. Floods continued to occur in various locations throughout the region until the end of September 2008. Figure 3 shows where floods occurred and location-specific impacts during this time.

Figure 3 Flood season mapping, September 2008

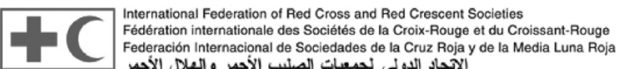

Floods season mapping September 2008

Floods in Western and Central Africa

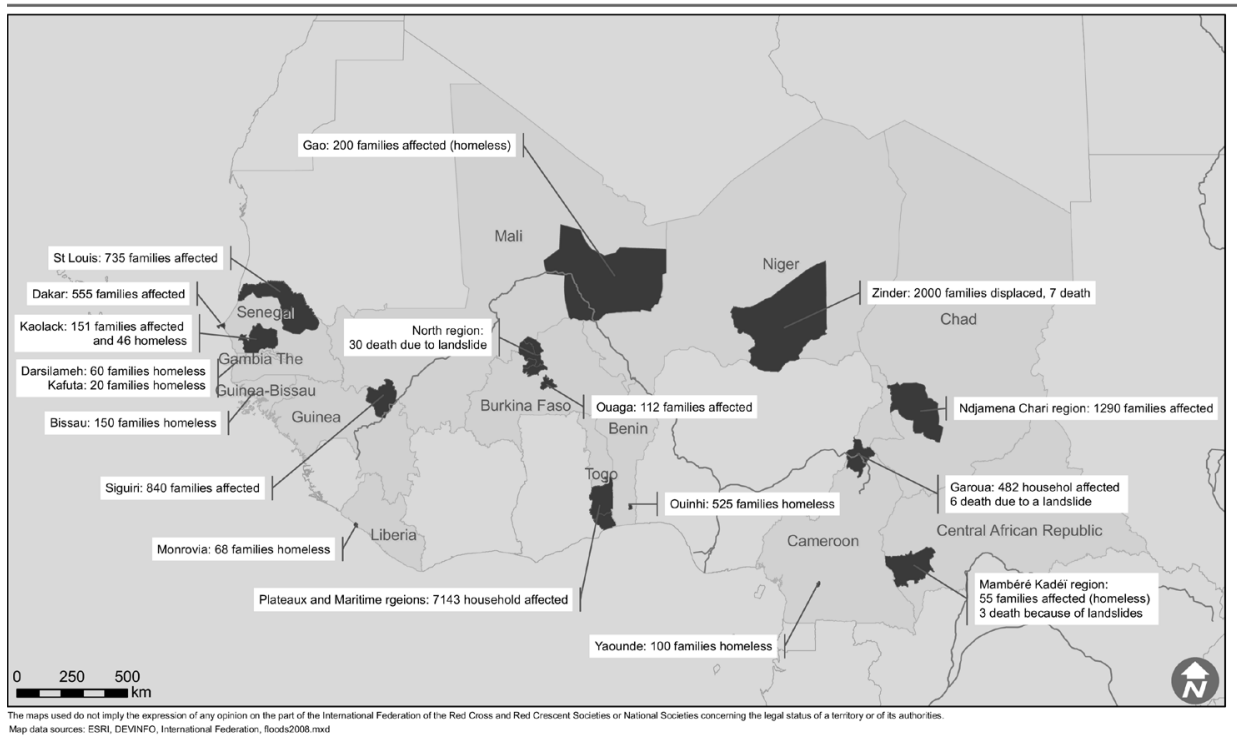

Source: communications staff member, IFRC, 2008. 


\section{Assessing whether early actions made a difference}

The actions taken by the IFRC WCAZ revealed progress in the use of climate forecasts in disaster management. However, a number of key questions remained: how effective was this first-time application of a seasonal forecast for disaster management operations by the Red Cross in West Africa? Were lives saved? Were costs lowered? Were flood operations improved? What helped? What bottlenecks hindered full implementation of the strategy?

Tracking the effectiveness of the interventions is essential to assess whether early actions based on seasonal forecast information constitute a viable strategy to help disaster managers reduce climate risks, particularly as they change and the need for adaptive strategies increases due to global climate change. If EWEA becomes systematised, the disaster management community will want to know where it is working well, so that best practices can be shared. Donors will also need evidence that early action improves the efficacy of disaster response and save lives in order to justify funding preparedness activities ahead of disasters based on longer-range forecasts. While they extend lead time to prepare, longer-range forecasts lack the level of certainty and spatial and temporal specificity that shorter-range forecasts offer and are less familiar to the donor community.

\section{Methods}

Available data pertaining to flood extent, impacts, preparedness, response, and associated costs were compared across three consecutive years in an effort to capture any benefits that might have been realised from the IFRC WCAZ's use of seasonal forecast information for advanced preparedness (see Table 3). The three years can be distinguished as follows:

- 2006-a year in which there was neither above-normal rainfall nor use of forecast information for early actions;

- 2007-a year in which rainfall was above-normal and no forecast-based early actions were taken; and

- 2008-a year in which there was above-normal rainfall and early actions were taken based on a seasonal forecast.

Although no two rainy seasons are ever quite the same, these three cases permit a comparison of impacts during two years with significant flooding (2007 and 2008) and a drier year with less flooding (2006), which acts as a baseline. Data on flood impacts and response costs were retrieved from a database maintained at IFRC Headquarters in Geneva, containing information from National Societies through Disaster Management Information System (DMIS) reports, Disaster Relief Emergency Fund (DREF) bulletins, emergency appeals, information bulletins, and operations updates. Although this database only reflects what was reported, it serves as one of the more comprehensive sources of information within the IFRC. However, in the process of 
requesting data on various indicators for comparison, it became clear that data have not been recorded in many of the categories that would serve as strong indicators for tracking the effectiveness and quantifying the benefits of implementing an early action strategy.

Disaster management coordinators and directors from the IFRC WCAZ and from National Red Cross Societies in Gambia, Ghana, Senegal, and Togo were also interviewed about their experiences of the 2007 and 2008 floods. The four National Societies interviewed were chosen on the basis that:

I. they were informed by the IFRC WCAZ of the seasonal forecast of enhanced probability of an above-normal rainy season;

2. they sent representatives to participate in the IFRC WCAZ's RDRT Team Leader's Training;

3. they completed flood-specific contingency plans; and

4. they were affected by floods in both 2007 and 2008 .

Staff members were asked a set of questions to gauge whether 2008 early actions taken by the IFRC WCAZ and within each National Society had improved their ability to respond, and if those early actions had made a difference for communities. Concrete benefits, challenges, and successes identified through interviews are summarised below.

\section{Results}

Available data presented in Table 3 show that the amount of money spent on flood management (preparedness and response) per beneficiary was roughly 33 per cent lower in 2008 than the amount of money spent on response alone, per beneficiary, in the two previous years. However, efforts to quantify decreases in costs per beneficiary are hampered by the fact that the IFRC WCAZ's definition of a beneficiary seems to have changed from 2007 to 2008: with the changing role of the Red Cross as a provider of early warning information, disaster managers are now inclined to count all Red Cross warning recipients as Red Cross beneficiaries. The extent to which this change in record-keeping happened in 2008 is unclear. Thus, for consistent comparison in future monitoring and evaluation, data would need to be tracked in two separate categories:

- the number of beneficiaries (defined as individuals who received a blanket, kitchen set, medical attention, rescue, resources, or water purification, inter alia, from the Red Cross); and

- the number of recipients of an early warning (defined as individuals whose lives and/or livelihoods potentially were saved because they took preparedness and risk reduction measures based on early warnings and instructions from the Red Cross). ${ }^{4}$ 
Table 3 Indicators of EWEA efficacy on an annual time scale

\begin{tabular}{|c|c|c|c|}
\hline WCAZ floods & 2006 & 2007 & 2008 \\
\hline $\begin{array}{l}\text { Number of floods Reported } \\
\text { by Red Cross in WCAZ }\end{array}$ & 9 & 32 & 29 \\
\hline Number of people affected & 103,892 & 816,198 & 155,322 \\
\hline Number of beneficiaries & 6,870 & 115,006 & 70,530 \\
\hline $\begin{array}{l}\text { Number of deaths due } \\
\text { to floods }\end{array}$ & 77 & 322 & 34 \\
\hline $\begin{array}{l}\text { Number of deaths per } \\
10,000 \text { affected people }\end{array}$ & 7.4 & 3.9 & 2.2 \\
\hline $\begin{array}{l}\text { Time scale of heavy precip- } \\
\text { itation warning, if any } \\
\text { (such as seasonal, } x \text { weeks, } \\
x \text { days, } x \text { hours, none). }\end{array}$ & None & None & $\begin{array}{l}\text { Seasonal to short term } \\
\text { (weeks and days) }\end{array}$ \\
\hline $\begin{array}{l}\text { What actions did the Red } \\
\text { Cross take leading up to } \\
\text { the flood? (For example, } \\
\text { evacuation or assistance } \\
\text { moving food stocks) }\end{array}$ & None & None & $\begin{array}{l}\text { Contingency plans in } 7 \text { out } \\
\text { of } 24 \text { National Societies. } \\
\text { Pre-positioned supplies. } \\
\text { RDRT Team Leader's } \\
\text { Training. }\end{array}$ \\
\hline Amount from DREF used & CHF 285,829 & CHF $1,484,290$ & CHF 563,449 \\
\hline $\begin{array}{l}\text { Amount of emergency } \\
\text { appeal }\end{array}$ & None & CHF 3,922,365 & CHF 1,520,349 \\
\hline Total financial resources & CHF 285,829 & CHF 5,406,655 & CHF 2,083,798 \\
\hline $\begin{array}{l}\text { Financial resources per } \\
\text { beneficiary }\end{array}$ & $\begin{array}{l}\text { CHF } 41.60 \text { per } \\
\text { beneficiary }\end{array}$ & $\begin{array}{l}\text { CHF } 47.01 \text { per } \\
\text { beneficiary }\end{array}$ & $\begin{array}{l}\text { CHF } 29.54 \text { per } \\
\text { beneficiary }\end{array}$ \\
\hline
\end{tabular}

Available data presented in Table 3 also show that the number of lives lost was reduced from 3.9 deaths per 10,000 affected in 2007 to 2.2 deaths per 10,000 affected in 2008. However, data are not yet tracked in categories that permit quantitative analysis alone to attribute directly the reduction in lives lost in the region as a whole to the use of forecast information for early actions. Until additional quantitative indicators are established to track the extent and severity of flooding, the time it takes for response by the Red Cross, and the extent to which early actions are implemented, inter alia, anecdotal evidence will have to suffice to identify instances where early actions are responsible for saving lives and enabling other benefits.

During interviews with staff at the IFRC WCAZ, it was reported that, in 2008, most countries received supplies needed in a matter of days post flooding. In contrast, in 2007 , the operation was an estimated 40 days late in responding to the floods. The lag time between a flooding disaster and the arrival of relief can cost lives, exacerbate health problems, and slow down the ability of a community to recover. Although it was not possible to quantify the number of lives saved by reduced response time, the significantly reduced response time itself undoubtedly serves as a key indicator of how forecast-based early actions improved the IFRC WCAZ's response. 
Disaster managers at the IFRC WCAZ noted that the RDRT Team Leader's Training in 2008 also made a difference. This training meant that the IFRC WCAZ had a team of people on standby specifically trained in flood response and disaster management, and that it was not relying on inactive or untrained volunteers. It meant too that disaster managers at the IFRC WCAZ did not need to deploy to the field and hence could focus on their regular responsibilities and support operations from headquarters. According to IFRC WCAZ staff, this new approach in 2008 moved the Red Cross into a more proactive role in broader disaster management efforts in the region (beyond those by the Red Cross itself), initiating activities by raising awareness and sharing forecast information with relevant organisations as well as with countries/ regions that were identified as confronting a high flood risk.

Interviews with IFRC WCAZ staff also indicated that, in 2008, there was a lower reliance among National Societies on international support through the DREF, due to investments made in advance that enabled them to mobilise local resources and be ready to respond quickly. In addition, the 2007 appeal was 2.5 times greater than the one issued in 2008 (see Table 3 ). The IFRC WCAZ attributes in part this reduced need for funding to the early actions taken in 2008.

During interviews with National Societies, benefits also were attributed to early actions based on the seasonal forecast:

Ghana: when forecasts for heavy rainfall indicated the possibility of excess water spillage from the Bagre and Kopienga reservoirs in Burkina Faso, early action was taken to avoid a repeat of the dam spillage and downstream flooding that occurred in 2007. A controlled release of the dam waters was agreed, and a two-week warning was issued prior to the release. The Ghana Red Cross Society (GRCS) took full advantage of this warning, mobilising volunteers to raise awareness of potential hazards, risks, and vulnerabilities in advance of the Bagre dam release. GRCS volunteers informed communities not to go near the riverbanks during the scheduled spillage of the dam, significantly contributing to the reduction of lives lost to flooding, from more than 30 in 2007 to 2 in 2008.

Togo: in spite of more people being affected by floods in 2008 than in 2007 , data tracked by IFRC Headquarters in Geneva indicate that fewer people in the country died from floods in 2008 than in 2007 ( $\mathrm{I} 6$ in 2008 as opposed to 25 in 2007). This reduction in flood-related deaths may be due to factors beyond the new forecastbased approach (such as remoteness of affected communities in 2007 and the large geographical area required for emergency response). However, staff at the Togo Red Cross believe the 2008 response was better and faster because they had received seasonal forecast information early on from the IFRC WCAZ, and because they had learned lessons from 2007. Early actions taken include those listed below:

I. A flood contingency plan was put in place.

2. The National Society held a training of trainers event in which 38 new volunteers were trained in disaster management. This increased the number of Togo Red Cross 
trainers from $\mathrm{I} 38$ to $\mathrm{I} 76$, a 27 per cent rise on the year before. The 38 new trainers also were trained comprehensively in disaster management, whereas trainers often were briefed only in disaster management, and not fully trained. For example, during the previous year, of the 138 trainers, only 20 were active trainers in first aid.

3. A communication system was established that allowed information to pass to and from national headquarters to contact focal points in the regions, to the districts, to community leaders, to communities.

4. Awareness of the seasonal forecast prompted development of an early warning system in the small community of Atiégou Zogbédji (population = 2,000). The system consists of colour-coded poles along the riverbed. The green colour at the bottom of the poles indicates safe water levels. The higher yellow mark advises that households should move food stocks and valuables to higher ground. Water at the highest red mark triggers evacuation. Volunteers and community leaders had been trained to monitor the water levels and to communicate warnings. The system had been developed in consultation with the community, so that an understanding of the warning's significance and evacuation plans were established ahead of time. With just 90 minutes' notice, the entire community was able to evacuate. When the community experienced flooding in 2008 , there was physical damage, but no loss of life.

Gambia: in response to being informed of the seasonal forecast and attending the IFRC WCAZ's RDRT Team Leader's Training, the Gambia Red Cross held its own National Disaster Response Team training, in which volunteers and branch officers from seven different branches were trained in disaster preparedness. As a result of this training and preparation, the National Society was able to perform a post-flood needs assessment and submit a funding request within two days of flooding.

Senegal: just two days into the RDRT Team Leader's Training, heavy rains and flooding began in Senegal. Although team leaders were not yet fully trained, the event provided them with the opportunity to assist the Senegal Red Cross with real damage and needs assessments. Throughout the rainy season, Senegal's disaster management department received information bulletins from ACMAD through the IFRC WCAZ. Early warnings from the IFRC WCAZ prompted the National Society to help flood-prone households to prepare for rains using sandbags and drainage systems. In one case, due to receiving an alert on I August, the National Society was able to carry out an assessment immediately after the floods on 2 August. Needs had been identified and addressed by 3 August, through distribution of non-food items.

\section{Discussion}

The above interviews with the IFRC WCAZ and National Society staff provided the opportunity to pinpoint successful approaches to their early action strategy, as well as the challenges that remain. 


\section{Successful approaches}

Monitoring forecasts on multiple time scales: upon receiving the seasonal forecasts in spring 2008, the IFRC WCAZ not only began to plan for above-normal rainfall, but it continued to monitor the situation through forecasts on multiple time scales. The seasonal forecast was supplemented by a monthly bulletin. Subsequently, it was important to monitor on shorter time scales, including Io-day (dekadal) forecasts, weekly forecasts, as well as three- and one-day forecasts, leading up to any anticipated extreme rainfall event. By monitoring on multiple time scales, uncertainty can be reduced, the geographic area at risk can be specified, and early actions can be accelerated prior to heavy rainfall events.

Using multiple information sources: rather than relying on one source of forecasts to determine action, the IFRC WCAZ made use of information from multiple providers, increasing confidence in the predictions. The IFRC WCAZ also used consensus-based seasonal forecasts, such as West Africa's annual PRESAO forum, in which seasonal forecasts are contributed by I 8 countries and a number of global producing services, including IRI, Météo France, and the United Kingdom's Met Office. Furthermore, the IFRC WCAZ utilised tools that combined the seasonal precipitation forecast with hydrology for flood risk mapping. The combination is important since a precipitation forecast is not a flood forecast.

Pre-positioning of emergency stocks at the zonal level based on seasonal forecasts: the IFRC WCAZ pre-positioned stocks in three locations throughout the region in 2008 , which could be accessed quickly in the event of a disaster. Seasonal forecasts do not show exactly where disasters will strike and National Societies do not always have sufficient warehouses for supplies. Even where warehouses are locked and guarded, there have been cases of supplies disappearing and being unaccounted for, and therefore not being available during an emergency. Maintaining the prepositioning of stocks in three locations (in a zone of 24 countries) provided a noregrets way of improving response time and increasing the likelihood that supplies would be used somewhere within the zone. The likelihood of floods is higher in the region than in any one country; pre-positioning supplies at the regional scale allows strategic placement and prevents the endangerment of stocks before exact locations of disasters are known.

Partnering with climate scientists to aid forecast interpretation: the IFRC WCAZ formed partnerships with climate institutes such as ACMAD and IRI in 2008 , and received support from the RCCC. Such partnerships are important in the initial stages of using long-range forecast information. Until end-users become accustomed to using seasonal forecasts, it is helpful for them to check with information providers to ensure they are interpreting the forecast accurately, and to discuss the limitations of the forecast in terms of skill, uncertainty, and the coarse resolution of model outputs, so that these aspects are well understood in decisionmaking processes. 


\section{Remaining challenges}

Communication and decision-making chains are not prepared to process forecast information: forecast information transmitted from the IFRC WCAZ in 2008 often reached National Societies in a timely manner, but it rarely reached communities at risk. One IFRC WCAZ disaster manager reported that, through the established communication networks, it is possible for urgent information to be transmitted between the IFRC WCAZ and communities within 90 minutes. However, these communication networks are not yet prepared to transmit forecast information efficiently.

The difficulty in communicating forecast information may be due in part to the lack of a systematised approach to monitoring forecasts on multiple time scales. A system set up with redundancy built in - so that the warning does not fail if a single designated individual is not there to receive it - would be the first step towards ensuring warning information is received and communicated.

The problem also may lie in the ability of forecast information to keep all links in communication network and decision-making chains activated. A single weak link can block the flow of important forecasts. It is important to ensure that every person receiving the information:

- has been designated to receive it and trained to interpret it;

- understands how the information should be used;

- comprehends its time sensitivity; and

- has been afforded both the authority to make decisions and the operational knowledge to mobilise the people, networks, and resources necessary for further communication and appropriate action.

Difficulties remain in mobilising donor support prior to a disaster: although progress has been made with respect to the Red Cross now allowing funds from the DREF to be used for preparedness activities, the larger donor community is still adjusting to the idea of providing for a disaster that is expected, but that has not yet struck. Mobilising funds before the media captures images of a 'disaster' on camera can be a challenge. While most donors understand that an ounce of prevention is worth a pound of cure, changing the donor framework takes time.

Early actions could be taken even earlier: in some cases benefits would have come from taking early action even sooner in West Africa. Flooding had begun in June in Senegal when the RDRT Team Leader's Training was being held. Furthermore, flooding had already occurred in many areas by the time supply shipments had been moved from Dubai, United Arab Emirates, to more accessible warehouses in the region. Seasonal forecasts indicating above-normal rainfall during the rainy season months of June-September also were issued in March and April, and while less certain, could have triggered earlier action and planning.

Limited capacity inhibits action: National Societies and disaster managers within the IFRC WCAZ mentioned repeatedly limited capacity as a significant obstacle to 
achieving full implementation of their disaster management strategies. Examples of such limitations include: scarce financial resources to transport non-food items; insufficient vehicles for National Societies to transport teams to conduct immediate assessments; delays experienced by supply trucks at country borders; and varying degrees of access to technology and communication tools. Disaster conditions also can slow down response in spite of preparedness measures - for instance, if bridges and roads are washed out. Political and bureaucratic processes also can slow down operations. In addition, some communities are too poor to take action based on warnings. Impoverished communities settled on flood plains, such as Senegal's Pikine, are continually vulnerable to floods, and yet can make little use of early warnings as they have few options to go elsewhere.

\section{Summary and conclusions}

In 2008, the IFRC WCAZ pioneered the use of seasonal climate forecasts within the Red Cross and Red Crescent Movement, as a component of an EWEA approach, anticipating rather than mainly responding to disasters. As a result, the response time at the IFRC WCAZ and National Society level was reduced significantly. Relief supplies reached flood victims within a matter of days, as opposed to a matter of weeks, thereby preventing further loss of life, illness, and setbacks to livelihoods. Capacity was enhanced at the zonal level and within National Societies, so that the Red Cross was ready. According to disaster managers, the use of early warnings and early actions quickly placed the Red Cross in a position to take on more of a leadership role, becoming a key player in disaster management in the region. In Ghana, early warning information was used to anticipate spillage of the Bagre dam, saving the lives of those who would otherwise have been in the path of the overflow. In Togo, where flooding affected more people in 2008 than in 2007 , it was actually in 2008 when early actions were taken. While Togo's overall reduction in lives lost cannot be attributed directly to EWEA, the establishment of the life-saving early warning system in Atiégou Zogbédji, prompted by the seasonal forecast, did save lives by enabling the entire community to escape an oncoming flood.

The IFRC WCAZ found a way to take advantage of existing climate information in spite of the many challenges to using and acting on climate forecasts. Consequently, its first attempt at using a seasonal forecast to enhance preparedness ahead of a flood season yielded concrete benefits. In the future, improved collection of data on preparedness activities, disaster responses, costs, and impacts will be essential for identifying successful practices. Careful collection of data also will help quantify savings from EWEA and demonstrate savings to donors.

Of even greater importance, this example has shown already that the employment of such forecasts and an EWEA approach at large can save lives and reduce setbacks to livelihoods. The West Africa case supports the idea that, with greater cooperation among disaster management institutions, climate and weather information providers, and donors, the use of climate forecasts for early warning at multiple time 
scales for effective early action can make an important contribution to better management of natural climate variability, as well as the increasing risks posed by climate change.

\section{Correspondence}

Lisette Martine Braman, Program Officer, Red Cross/Red Crescent Climate Centre, PO Box 28I20, 2502 KC The Hague, The Netherlands. Telephone: +3I 704455886 ; fax: +3I 7044 55 7I2; e-mail: climatecentre@climatecentre.org

\section{Endnotes}

I Lisette Martine Braman is Program Officer at the Red Cross/Red Crescent Climate Centre, Netherlands, and a Staff Associate at the International Research Institute for Climate and Society, The Earth Institute, Columbia University, United States; Maarten Krispijn van Aalst is Associate Director and Lead Climate Specialist at the Red Cross/Red Crescent Climate Centre, Netherlands; Simon J. Mason is Climate Program Leader at the International Research Institute for Climate and Society, The Earth Institute, Columbia University, United States; Pablo Suarez is Associate Director of Programs at the Red Cross/Red Crescent Climate Centre, Netherlands; Youcef Ait-Chellouche is Disaster Management Coordinator at the International Federation of Red Cross and Red Crescent Societies, West and Central Africa Zone, Senegal; and Arame Tall is a PhD Candidate at The Johns Hopkins University, Paul H. Nitze School of Advanced International Studies, United States.

2 For the purposes of this paper, climate refers to the average weather over time: months to years to millennia.

3 See http://www.unisdr.org/eng/hfa/hfa.htm.

4 Braman (2009) contains further discussion of indicators for future tracking and quantitative analysis of the 2008 operations.

\section{References}

ACMAD (African Center for Meteorological Applications to Development) (2008) Climate Watch Africa Bulletin. 6 (June).http://www.wamis.org/countries/acmad/acmad_mon20o806_en.pdf (accessed on 5 September 2012).

Adeel, Z. and M.H. Glantz (200I) 'El Nino of the century: once burnt, twice shy?' Global Environmental Change. II (2). pp. I7I-I74

Braman, L. (2009) Early Warning, Early Action: An Evaluation of IFRC West and Central Africa Zone Flood Preparedness and Response, 2008. Technical report prepared for the IFRC West and Central Africa Zone and the Red Cross/Red Crescent Climate Centre. http://www.climatecentre.org/downloads/ File/ewea_an_evaluation_of_ifrc_west_and_central_africa.pdf (accessed on I4 August 20I2).

Broad, K. and S. Agrawala (2000) 'The Ethiopia Food Crisis: Uses and Limits of Climate Forecasts'. Science. 289 (5485). pp. I693-I694.

Buizer, J.L., J. Foster and D. Lund (2000) 'Global impacts and regional actions: preparing for the I997-98 El Niño’. Bulletin of the American Meteorological Society. 8I (9). pp. 2I 2 I-2 I39.

Christensen, J.H. et al. (2007) 'Regional climate projections'. In S. Solomon et al. (eds.) Climate Change 2007: The Physical Science Basis. Contribution of Working Group I to the Fourth Assessment Report of the Intergovernmental Panel on Climate Change. Cambridge University Press, Cambridge. pp. 847-940. 
DFID (Department for International Development) (2009) 'Preparing for disaster in Mozambique'. 8 December. http://reliefweb.int/report/mozambique/preparing-disaster-mozambique (accessed on I4 August 2012).

Glantz, M. (200I) Once Burned, Twice Shy? Lessons Learned from the 1997-98 El Niño. United Nations University, New York, NY.

Haile, M. (2005) 'Weather patterns, food security and humanitarian response in Sub-Saharan Africa'. Philosophical Transactions: Biological Sciences. 360(I463). pp. 2169-2I82.

Hellmuth, M.E., A. Moorhead, M.C. Thomson and J. Williams (eds.) (2007) Climate Risk Management in Africa: Learning from Practice. International Research Institute for Climate and Society, Columbia University, New York, NY.

Hossain, E., H. Imam, S. Alam and M. Hoque (2000) The Assessment of El Niño Impacts and Responses: Strategies for the 1997-98 El Niño Event in Bangladesh. Bangladesh Public Administration Training Centre, Savar, Dhaka.

IFRC (International Federation of Red Cross and Red Crescent Societies) (I999) World Disasters Report 1999. IFRC, Geneva. http://desastres.usac.edu.gt/documentos/pdf/eng/doci I $834 /$ doci I 834 .htm (accessed on 14 August 2012).

IFRC (2008a) Early Warning > Early Action. Technical report. IFRC, Geneva. http://www.climatecentre. org/downloads/File/reports/Early\%2oWarning\%2oEarly\%20Action\%202008.pdf (accessed on 29 January 20I0).

IFRC (2008b) 'International Federation launches emergency appeal for floods preparedness in West and Central Africa'. II July. http://www.ifrc.org/fr/nouvelles/communiques-de-presse/general/ international-federation-launches-emergency-appeal-for-floods-preparedness-in-west-andcentral-africa/ (accessed on I4 August 2012).

IFRC (2009) World Disasters Report 1999: Focus on Early Warning, Early Action. IFRC, Geneva. http:// www.ifrc.org/Global/WDR2009-full.pdf (accessed on I4 August 2012).

IPCC (Intergovernmental Panel on Climate Change) (2007) Fourth Assessment Report. http://www. ipcc.ch/publications_and_data/publications_and_data_reports.shtml (accessed on I4 August 20I2).

Kleiner, K. (2010) 'Climate Science in 2009'. Nature Reports Climate Change. I7 December. http://www. nature.com/climate/20Io/Ioor/full/climate.20IO.I34.html (accessed on I4 August 20I2).

Mason, S.J. (2008) "“Flowering walnuts in the wood" and other bases for seasonal climate forecasting'. In M.C. Thomson and R.G. Herrera (eds.) Climatic Change, Seasonal Forecasts and Human Health: Advances in Global Change Research (AGLO). Springer, Dordrecht. pp. I3-29.

O’Brien, G., P. O’Keefe, J. Rose and B. Wisner (2006) 'Climate change and disaster'. Disasters. 30 (I). pp. $64-80$.

Patt, A., L. Ogallo and M. Hellmuth (2007a) 'Learning from to years of climate outlook forums in Africa'. Science. 318(5847). pp. 49-50.

Patt, A. and J. Winkler (2007b) Applying Climate Information in Africa: An Assessment of Current Knowledge. Report prepared for the United States National Oceanic and Atmospheric Administration. http://www.iiasa.ac.at/Admin/PUB/Documents/XO-07-006.pdf (accessed on I4 August 20I2).

Suarez, P. (2009) Linking Climate Knowledge and Decisions: Humanitarian Challenges. The Pardee Papers. No. 7. Frederick S. Pardee Center for the Study of the Longer-Range Future, Boston University, Boston, MA.

Tadesse, T. et al. (2008) 'The need for integration of drought monitoring tools for proactive food security management in Sub-Saharan Africa'. Natural Resources Forum. 32 (4). pp. 265-279.

Tall, A. et al. (2012) 'Using seasonal climate forecasts to guide disaster management: the Red Cross experience during the 2008 West Africa floods'. International Journal of Geophysics. Volume 20I2. Article ID 9860I6. http://www.hindawi.com/journals/ijgp/2012/9860I6/ (accessed on 5 September 20I2).

The Economist (2005) 'Starving for the cameras'. 20 August. 376(8440). pp. IO-II.

van Aalst, M.K. (2006) 'The impacts of climate change on the risk of natural disasters'. Disasters. 3O(I). pp. 5-I8. 
van Aalst, M.K, S. Frankhauser, S. Kane and K. Sponberg (2000). Climate Information and Forecasting for Development: Lessons Learned from the 1997/98 El Niño. Environment Department Papers. Climate Change Series. No. 79. The World Bank, Washington, DC.

WMO (World Meteorological Organization) (2010) Position Paper on Global Framework for Climate Services. Draft report submitted by the World Meteorological Organization to the High-Level Taskforce for the Global Framework for Climate Services. http://www.wmo.int/pages/gfcs/documents/ GFCS_Position_Paper_DRAFT_REV_I_en_I.pdf (accessed on I4 August 20I2). 